\title{
Illness cognition as a predictor of exercise habits and participation in cardiac prevention and rehabilitation programs after acute coronary syndrome
}

\author{
Orna Reges ${ }^{1,2,3^{*}}$, Noa Vilchinsky ${ }^{4}$, Morton Leibowitz ${ }^{2,5}$, Abdulrahem Khaskia ${ }^{3}$, Morris Mosseri ${ }^{3}$ and Jeremy D Kark ${ }^{1}$
}

\begin{abstract}
Background: Despite well-established medical recommendations, many cardiac patients do not exercise regularly either independently or through formal cardiac prevention and rehabilitation programs (CPRP). This non-adherence is even more pronounced among minority ethnic groups. Illness cognition (IC), i.e. the way people perceive the situation they encounter, has been recognized as a crucial determinant of health-promoting behavior. Few studies have applied a cognitive perspective to explain the disparity in exercising and CPRP attendance between cardiac patients from different ethnic backgrounds. Based on the Health Belief Model (HBM) and the Common Sense Model (CSM), the objective was to assess the association of IC with exercising and with participation in CPRP among Jewish/majority and Arab/minority patients hospitalized with acute coronary syndrome.

Methods: Patients ( $N=420$ ) were interviewed during hospitalization (January-2009 until August- 2010) about IC, with 6-month follow-up interviews about exercise habits and participation in CPRP. Determinants that predict active lifestyle and participation in CPRP were assessed using backward stepwise logistic regression.

Results: Perceived susceptibility to heart disease and sense and personal control were independently associated with exercising 6 months after the acute event $(\mathrm{OR}=0.58,95 \% \mathrm{Cl}: 0.42-0.80$ and $\mathrm{OR}=1.09,95 \% \mathrm{Cl}: 1.02-1.17$, per unit on a 5 -point scale). Perceived benefits of regular exercise and a sense of personal control were independently associated with participation in CPRP $(\mathrm{OR}=1.56,95 \% \mathrm{Cl}: 1.12-2.16$ and $\mathrm{OR}=1.08,95 \% \mathrm{Cl}: 1.01-1.15$, per unit on a 5 -point scale). None of the IC variables assessed could explain the large differences in health promoting behaviors between the majority and minority ethnic groups.

Conclusions: IC should be taken into account in future interventions to promote physical activity and participation in CPRP for both ethnic groups. Yet, because IC failed to explain the gap between Arab and Jewish patients in those behaviors, other explanatory pathways such as psychological state or cultural views should be considered as potential areas for further research.
\end{abstract}

\section{Background}

Cardiovascular disease (CVD) is a leading cause of death worldwide [1]. In Israel, heart disease is the second most common cause of death among the general population, and the main cause among people aged 75 or older [2].

\footnotetext{
* Correspondence: orna.reges@gmail.com

'Hebrew University-Hadassah School of Public Health and Community Medicine, Ein Kerem, Jerusalem, Israel

${ }^{2}$ Clalit Research Institute, Tel-Aviv, Israel

Full list of author information is available at the end of the article
}

In order to prevent recurrence after an acute coronary event, patients are advised to change lifestyle habits that are major risk factors for CVD. Specifically, there are compelling recommendations to adopt an active lifestyle $[3,4]$. Despite this, there continue to be large segments of the patient population that do not exercise on their own volition nor avail themselves of organized rehabilitation services. There is also an increasing awareness that ethnic minorities figure prominently among those population groups that do not adhere to these recommendations $[5,6]$.

\section{Ciomed Central}

(c) 2013 Reges et al.; licensee BioMed Central Ltd. This is an open access article distributed under the terms of the Creative Commons Attribution License (http://creativecommons.org/licenses/by/2.0), which permits unrestricted use, distribution, and reproduction in any medium, provided the original work is properly cited. 
Participation in Cardiac Prevention and Rehabilitation programs (CPRP) is probably the most effective way to promote engagement in an active life routine. Indeed, CPRP is recommended by the major international guidelines following an acute coronary event $[7,8]$. Despite these recommendations, once again minorities are known to participate less in CPRP worldwide [9-11]. We have shown substantial differences between the Jewish majority and the Arab minority in Israel with regards to participation in CPRP, $61.1 \%$ and $17.2 \%$, respectively [12].

An examination of patient-related barriers is essential to promote adoption of an active lifestyle either independently or through CPRP participation. Theories of health behavior emphasize that the way people perceive the situation they encounter is a crucial determinant of healthpromoting behavior [13]. It is therefore plausible to assume that the challenge of equalizing services in minority ethnic groups also depends on understanding patients' health and illness cognitions, i.e. attitudes and perceptions of their illness and the ways to cope with it. This report, theoretically based on the Health Belief Model (HBM) and the Common Sense Model (CSM), focuses on the individual's illness cognitions as contributing to adoption of an active lifestyle and participation in CPRP among Jewish and Arab patients following acute coronary syndrome (ACS).

The Health Belief Model (HBM) [14], which has been extensively applied to explore the association between individuals' cognitive beliefs and health behavior, is considered an effective tool for preventive health interventional planning [15].

The original model includes the following dimensions: perceived susceptibility (subject's perception of the risk of contracting a condition); perceived severity (the medical, clinical and social consequences of the illness); perceived benefits (the subject's estimate of the effectiveness of a given intervention); and perceived barriers (an estimate of possible negative consequences of a given behavior/ intervention).

Aside from focusing on the illness situation per se, a substantial body of literature in the psychology arena has also focused on variables which characterize the patient. One important variable that has been shown to be associated with participation in CPRP is belief that the illness could be controlled [16]. This variable is particularly relevant to the current study since it focuses on the illness cognitions of two different ethnic groups, which may differ in their perceptions regarding control over the disease [17]. The current study followed Levental's well-known common sense model (CSM) and focused specifically on the contribution of both personal control and treatment control to self-adaptive physical activity or participation in CPRP after ACS $[18,19]$. Personal control evaluates one's subjective assessment of his/her ability to deal with the illness whereas treatment control taps one's intuitive understanding of the efficacy of one's treatment.

Although many studies have demonstrated the important contribution of illness cognition (IC) to the adoption of an active lifestyle as well as participation in CPRP [16,20-25], exploration of these associations in minority populations has been limited [26-28].

Therefore, the current longitudinal prospective study examined the contribution of illness cognition (the four HBM components together with the two CSM aspects of perceived control) to the adoption of an active lifestyle and participation in CPRP among Jewish (majority) and Arab (minority) patients hospitalized with acute coronary syndrome in an Israeli community hospital.

\section{Methods}

The methods of the present study have been previously reported [12,29] and are summarized below.

\section{Study population}

All patients residing in the catchment area of the Meir Medical Center in Israel admitted to the coronary care unit (CCU) whether for acute myocardial infarct (MI) or for intervention for acute coronary syndrome (ACS) between January 2009 and August 2010 were registered for the study. Distinction between MI and ACS was based on: typical history, positive EKG changes, positive troponin levels, and adjudication by a senior cardiologist. Exclusion criteria were: 1 . Severe physical or mental disability that prevent participation in physical activities, 2 . Inability to commit to the study (non-permanent resident in Israel, prisoners, homeless, drug addicts or alcoholics) 3. Previous participation in CPRP, 4. Lack of adequacy in Hebrew or Arabic, and 5. Immediate transfer to another institution for further treatment.

There were 649 eligible patients of whom 501 consented to be interviewed at baseline (77.2\%). At six months follow up 420 consented to be interviewed, 43 refused follow up interviews, 5 had died, 26 could not be located, and 7 could not be interviewed due to their emotional/physical state yielding an $83.8 \%$ response. Response rates were similar between Arabs and Jews. There were higher response rates at follow up among men versus women, among patients admitted directly to the CCU versus transfers for interventional treatment, and among MI versus ACS patients.

The final study sample included 304 Jews (72.4\%) and 116 Arabs (27.6\%) with mean age of $59.6 \pm 10.9$ years, $84.5 \%$ were male, and $71.7 \%$ had a discharge diagnosis of acute myocardial infarction (compared to $28.3 \%$ with unstable angina).

Informed consent was obtained from each patient. The study was authorized by the Meir Hospital Institutional Review Board. 


\section{Data collection and variable definition}

Patients were interviewed face-to-face (by interviewers proficient in Hebrew and Arabic) as soon as they were stable (2-5 days after admission) regarding their sociodemographic characteristics and medical information, exercise habits, and illness cognition as described below. Information regarding participation in CPRP was gathered by telephone 6 months after discharge.

Socio-demographic characteristics included ethnicity (Jews/Arabs), gender, age, place of birth, marital status, education level (highest certificate/degree earned), employment status, economic situation, subjective socioeconomic position (SEP) [30], religiosity, and HMO membership. The SEP has been used previously in studies with ethnically diverse samples [31,32].

Medical information included the hospitalization unit (CCU or Internal medicine), diagnosis (MI or unstable angina), and history of CHD (yes/no).

Leisure-time physical activity was estimated at baseline and at follow up based on a modification of the Minnesota leisure-time physical activity (LTPA) quantitative questionnaire, which estimates activity level [33]. In this present study participants were defined as sedentary if there was no self-reported level of activity or as active if engaged in any LTPA.

To assess participation in CPRP, patients were asked at the follow-up interview whether they had joined any CPRP (defined as rehabilitation and not convalescence) after the index hospitalization.

Illness cognition included the HBM components and cure/ control components (personal control and treatment control). The HBM components were measured using a questionnaire developed by Mirotznik et al. [34] for explaining attendance at a supervised CHD exercise program, based in a community center. Perceived susceptibility to CHD (3 items), perceived severity of CHD (11 items), perceived benefits of exercise ( 9 items), and perceived costs of exercise (5 items) were measured on a five-point Likert scale from 1 (low) to 5 (high). The average score for each subscale was used. The cure/control components were measured by using the revised illness perception questionnaire (IPQ-R) [35]. The full questionnaire introduced five components for assessing the patients' cognitive representations of their illness. For the purpose of this study, personal control and self-efficacy beliefs (personal control, 6 items) and beliefs in the treatment or recommended advice (treatment control, 5 items) were used. Each items was measured on a five-point Likert scale from 1 (strongly agree) to 5 (strongly disagree). The sum score for each subscale was used. A high score represents positive beliefs about the controllability.

\section{Data analysis}

Statistical analyses were carried out using SPSS-18 software. In unadjusted analyses, chi-square or Fisher exact tests for categorical variables and the t-test for continuous variables were used to evaluate between-group differences and assess associations between variables.

A backward stepwise logistic regression procedure with three blocks of variables and with an exit significance level of $\mathrm{p}>0.2$ was performed to determine the independent associations between the illness representations and physical activity six months after discharge. The first block included ethnicity, gender, age, and physical activity at baseline. The second block included additional socio-demographic characteristics and the medical variables, and the third block included the illness cognition variables. In order to explore the independent association between the potential cognitive barriers and participation in CPRP, the backward stepwise logistic regression procedure was repeated as above without including physical activity habits.

\section{Results}

Arab patients reported a higher rate of a sedentary/inactive lifestyle 6 months after the index event than Jewish patients (53\% vs. 18.2\%).

Unadjusted Analyses (Table 1) Pointed to significant differences between Jews and Arabs in the illness cognition components. Compared to Jewish patients, Arabs had higher perceived susceptibility to CHD, higher perceived cost of exercise, lower perceived benefits of exercise, and lower perceived personal and treatment control. As for the association between illness cognition and adoption of an active lifestyle six months after discharge, active patients reported lower perceived susceptibility than sedentary patients in both ethnic groups [average(SD): 2.97 (0.88) vs. 3.49 (0.86), $\mathrm{p}<0.001$ among Jews and 3.06 (1.03) vs. 3.50 (0.97) among Arabs, $\mathrm{p}<0.05]$, higher perceived personal control among Arabs only [average(SD): 22.89 (3.62) vs. 21.32 (3.35), $\mathrm{p}<0.05$ ] , and a higher perceived benefit of exercise that was evident only in Jews [average (SD): 4.00 (0.72) vs. 3.69 (0.83), $\mathrm{p}<0.05]$. Concerning participation in CPRP, participants had higher perceived personal control in both ethnic groups [average (SD): 24.21(3.87) vs. 22.22 (4.54), $\mathrm{p}<0.001$ among Jews and 23.56 (3.46) vs. 21.80 (3.53) among Arabs, $\mathrm{p}<0.05]$.

Multivariable logistic modeling (Table 2) confirmed an independent inverse association between perceived susceptibility to CHD (OR $=0.58,95 \% \mathrm{CI}$ : 0.42-0.80) and a positive association between perceived personal control $(\mathrm{OR}=1.09,95 \% \mathrm{CI}: 1.02-1.17)$ with exercising six months after discharge. In addition the following variables were predictors: exercise habits at the index hospitalization, ethnicity (ORArab/Jews $=0.43$, 95\% CI: $0.23-0.80$ ), and education (ORhigh/low $=1.42$, 95\% CI: 1.10-1.82). As for the predictors of participation in CPRP (Table 3), perceived benefits of regular exercise and personal control were found to be independently associated with participation in CPRP $(\mathrm{OR}=1.56,95 \% \mathrm{CI}: 1.12-2.16$ 
Table 1 differences between Jews and Arabs in health belief model components and in cure/control components

\begin{tabular}{|c|c|c|c|c|c|c|}
\hline \multirow[t]{2}{*}{ Cognitive component } & \multicolumn{2}{|c|}{ Jews } & \multicolumn{2}{|c|}{ Arabs } & \multicolumn{2}{|c|}{ Total } \\
\hline & (n) & $M \pm S D$ & (n) & $M \pm S D$ & $(n)$ & $M \pm S D$ \\
\hline Perceived susceptibility to CHD & 303 & $3.06 \pm 0.90$ & 113 & $3.29 \pm 1.02^{*}$ & 416 & $3.12 \pm 0.93$ \\
\hline Perceived severity of $\mathrm{CHD}$ & 303 & $3.35 \pm 1.02$ & 113 & $3.50 \pm 0.95$ & 416 & $3.39 \pm 0.98$ \\
\hline Perceived benefits of exercise & 304 & $3.87+0.78$ & 112 & $3.64 \pm 0.75^{* *}$ & 416 & $3.81 \pm 0.78$ \\
\hline Perceived cost of exercise & 304 & $2.60 \pm 0.66$ & 111 & $2.87+0.73^{* * *}$ & 415 & $2.67 \pm 0.69$ \\
\hline Personal control & 302 & $23.44 \pm 4.25$ & 111 & $22.11 \pm 3.5^{* *}$ & 413 & $23.09 \pm 4.11$ \\
\hline Treatment control & 302 & $21.08 \pm 2.95$ & 111 & $19.92+2.57^{* * *}$ & 413 & $20.77 \pm 2.89$ \\
\hline
\end{tabular}

${ }^{*} p<0.05 * * p<0.01{ }^{* * *} p<0.001$.

and $\mathrm{OR}=1.08,95 \% \mathrm{CI}: 1.01-1.15$, respectively, per unit on a 5 -point scale), in addition to the following predictors: ethnicity (ORArab/Jews $=0.14$, 95\% CI: 0.07-0.27), discharge diagnosis (ORUAP/AMI $=0.38,95 \% \mathrm{CI}: 0.22-0.65$ ), and history of IHD (ORno/yes $=0.52$, 95\% CI: 0.31-0.87).

Thus, the strong contribution of ethnicity to both independent physical activity and CPRP-based physical activity persisted, notwithstanding the significant contribution of several of the illness cognitions assessed.

Addition of interaction terms of ethnicity with each of the illness cognitions yielded no significant contribution.

\section{Discussion}

In 2012 Stuart-Shor et al. [36] published a comprehensive review of the significant impact behavioral factors have on explaining the substantial differences in cardiovascular outcomes in ethnic minorities. This review extensively discussed strategies for altering disease perceptions and made special mention of "cross-cultural" factors including the meaning of illness and wellness as being important in altering patient behavior.

The current findings demonstrated the contribution of perceived susceptibility to $\mathrm{CHD}$, perceived benefit of

Table 2 Associations of socio-demographic characteristics, medical variables, and cognitive variables with exercise habits six months after index hospitalization assessed by backward stepwise logistic regression ${ }^{i}$

\begin{tabular}{|c|c|c|c|}
\hline variable & $\begin{array}{c}\text { Block-1 } \\
\text { Odds ratio }{ }^{\mathrm{ii}}(95 \% \mathrm{Cl}), \mathrm{P} \text { value }\end{array}$ & $\begin{array}{c}\text { Block-2 } \\
\text { Odds ratioii }(95 \% \mathrm{Cl}), \mathrm{P} \text { value }\end{array}$ & $\begin{array}{c}\text { Block-3 } \\
\text { Odds ratio }{ }^{\mathrm{ii}}(95 \% \mathrm{Cl}), \mathrm{P} \text { value }\end{array}$ \\
\hline Exercise at baseline & $3.89(2.11-7.16), P<0.001$ & $3.68(1.94-6.99), P<0.001$ & 3.91 (1.99-7.68), $P<0.001$ \\
\hline Ethnicity & $0.29(0.17-0.50), P<0.001$ & $0.39(0.22-0.71), P=0.002$ & $0.43(0.23-0.80), p=0.007$ \\
\hline Gender & $0.50(0.25-1.03), P=0.059$ & $0.48(0.22-1.01), P=0.054$ & $0.55(0.25-1.20), p=0.134$ \\
\hline Age & $1.02(1.00-1.05), P=0.112$ & $1.03(1.00-1.06), P=0.035$ & $1.03(1.00-1.06), p=0.057$ \\
\hline Education & & $1.32(1.04-1.67), P=0.022$ & $1.42(1.10-1.82), p=0.006$ \\
\hline Economic situation & & $0.75(0.59-0.96), P=0.020$ & $0.81(0.63-1.04), p=0.093$ \\
\hline HMO membership & & $1.54(0.83-2.86), P=0.174$ & $1.47(0.78-2.79), p=0.235$ \\
\hline Diagnosis & & $2.07(1.04-4.13), P=0.040$ & $1.89(0.93-3.84), p=0.080$ \\
\hline Hospitalization unit & & $0.55(0.29-1.06), P=0.073$ & $0.57(0.30-1.11), p=0.098$ \\
\hline History of IHD & & $0.59(0.34-1.03), P=0.065$ & $0.75(0.41-1.36), p=0.340$ \\
\hline Perceived susceptibility to CHD & & & $0.58(0.42-0.80), p=0.001$ \\
\hline Perceived severity of $\mathrm{CHD}$ & & & $1.26(0.90-1.75), p=0.173$ \\
\hline Perceived benefits of exercise & & & $0.75(0.51-1.12), p=0.158$ \\
\hline \multirow[t]{2}{*}{ Personal control } & & & $1.09(1.02-1.17), p=0.016$ \\
\hline & Nagelkerke $R^{2}=0.23$ & Nagelkerke $R^{2}=0.31$ & Nagelkerke $R^{2}=0.36$ \\
\hline
\end{tabular}

$\mathrm{i}$ to exit $>0.20$, within each block, so that variables in earlier blocks were retained in the final model even if their $\mathrm{P}$ values with the introduction of subsequent blocks increased to $>0.2$.

ii Values: Exercise habits after six months: $0=$ no; $1=$ yes (dependent variable); Variables included in block-1: Ethnic group: $0=$ Jews, $1=$ Arabs; Gender: $0=$ male, 1 = female; Age introduced as continuous variable (years); Exercise habits at index hospitalization: $0=$ no; $1=$ yes; Variables included in block-2: SEP introduced as an ordinal variable ( 10 point scale from $1=$ the least well off to $10=$ the best off); Birth place: $0=$ Israel, $1=$ other; Marital status: $0=$ married, $1=$ other; Education level introduced as an ordinal variable ( 5 point scale from $1=$ no formal education to $5=$ Academic Education); Religiosity introduced as an ordinal variable ( 3 point scale from $1=$ Secular to $3=$ Religious); Employment status: $1=$ yes; 2 =no; economic situation introduced as ordinal variable (6-point scale from $1=$ excellent to 6 = very bad); HMO membership: $1=$ Clalit, $2=$ other; Diagnosis:0 = Myocardial infarction, $1=$ Unstable Angina; History of IHD: $0=$ no, $1=$ yes; hospitalization unit: 1 = cardiac care unit, 2 = internal medicine; Variable included in block-3: Perceived susceptibility to CHD, Perceived severity of CHD, Perceived benefits of exercise, Perceived cost of exercise, Personal control, Treatment control introduced as an ordinal variable $(5$ point scale from $1=$ not at all to $5=$ very much. 
Table 3 Associations of socio-demographic characteristics, medical variables, and cognitive variables with participation in CPRP six months after index hospitalization assessed by backward stepwise logistic regression ${ }^{i}$

\begin{tabular}{|c|c|c|c|}
\hline \multirow[t]{2}{*}{ variable } & Block-1 & Block-2 & Block-3 \\
\hline & Odds ratio ${ }^{\mathrm{ii}}(95 \% \mathrm{Cl}), \mathrm{P}$ value & Odds ratio $(95 \% \mathrm{Cl}), \mathrm{P}$ value & Odds ratio ${ }^{\mathrm{ii}}(95 \% \mathrm{Cl}), \mathrm{P}$ value \\
\hline Ethnicity & $0.11(0.06-0.19), p<0.001$ & $0.12(0.06-0.23), p<0.001$ & $0.14(0.07-0.27), p<0.001$ \\
\hline Age & $0.97(0.95-0.99), p=0.009$ & $0.98(0.96-1.01), p=0.143$ & $0.99(0.97-1.02), p=0.475$ \\
\hline SEP & & $1.14(1.01-1.29), p=0.035$ & $1.11(0.98-1.26), p=0.099$ \\
\hline Marital status & & $0.59(0.32-1.10), p=0.097$ & $0.60(0.31-1.14), p=0.119$ \\
\hline Education & & $1.22(0.99-1.49), p=0.062$ & $1.21(0.98-1.49), p=0.073$ \\
\hline HMO membership & & $0.63(0.37-1.09), p=0.096$ & $0.58(0.33-1.01), p=0.054$ \\
\hline Diagnosis & & $0.33(0.22-0.65), p<0.001$ & $0.38(0.22-0.65), p<0.001$ \\
\hline History of IHD & & $0.55(0.33-0.90), p=0.018$ & $0.52(0.31-0.87), p=0.013$ \\
\hline Perceived benefits of exercise & & & $1.56(1.12-2.16), p=0.009$ \\
\hline \multirow[t]{2}{*}{ Personal control } & & & $1.08(1.01-1.15), p=0.017$ \\
\hline & Nagelkerke $R^{2}=0.21$ & Nagelkerke $\mathrm{R}^{2}=0.32$ & Nagelkerke $R^{2}=0.36$ \\
\hline
\end{tabular}

i $P$ to exit $>0.20$, within each block, so that variables in block 1 (ie. age) were retained in the final model even if their $\mathrm{P}$ values with the introduction of subsequent blocks increased to $>0.2$.

iivalues: Exercise habits after six months: $0=$ no; $1=$ yes (dependent variable); Variables included in block-1: Ethnic group: $0=$ Jews, $1=$ Arabs; Gender: $0=$ male, $1=$ female; Age introduced as continuous variable (years) Variables included in block-2: SEP introduced as an ordinal variable $(10$ point scale from $1=$ the least well off to $10=$ the best off); Birth place: $0=$ Israel, $1=$ other; Marital status: $0=$ married, $1=$ other; Education level introduced as an ordinal variable $(5$ point scale from 1 = no formal education to $5=$ Academic Education); Religiosity introduced as an ordinal variable ( 3 point scale from $1=$ Secular to $3=$ Religious); Employment status: 1 =yes; $2=$ no; economic situation introduced as ordinal variable (6-point scale from $1=$ excellent to $6=$ very bad); HMO membership: $1=$ Clalit, 2 =other; Diagnosis:0 = Myocardial infarction, $1=$ Unstable Angina; History of IHD: $0=$ no, $1=$ yes; hospitalization unit: $1=$ cardiac care unit, $2=$ internal medicine; Variable included in block-3: Perceived susceptibility to CHD, Perceived severity of CHD, Perceived benefits of exercise, Perceived cost of exercise, Personal control, Treatment control introduced as an ordinal variable $(5$ point scale from $1=$ not at all to $5=$ very much.

regular exercise, and sense of personal control to adoption of an active lifestyle or participation in CPRP among Jewish and Arab ACS patients. Perceived susceptibility and sense of personal control were independently associated (inversely and positively, respectively) with an active lifestyle 6 months after the acute event. Perceived benefits of regular exercise was not found to be associated directly with an active lifestyle but was associated with participation in CPRP - a surrogate for organized physical activity. Sense of personal control was also associated with participation in CPRP.

It seems that cardiac patients who conceive themselves to be highly predisposed to additional cardiac events refrain from exercising on a regular basis. A possible explanation may be that these patients misconceive this behavior as harmful to their health. Interestingly, susceptibility was not associated with joining CPRP. Altering this perception by reassuring patients with regard to the safety and efficacy of CPRP may be an effective intervention to overcome this barrier.

In the same vein, patients who conceive exercise to be beneficial compared with patients who overlooked these benefits tend to join CPRP but not necessarily to engage in physical activity on their own. Thus, CPRP seems to be a useful scaffold for initiating an active life style for those patients who already regard this behavior as beneficial. Unfortunately, those patients who do not perceive exercise as beneficial tend to participate less in CPRP and, as a consequence, might be at higher risk for recurrence of cardiac events. Patients who perceived themselves as capable of controlling their illness were more likely to initiate an active lifestyle and to participate in CPRP. Therefore, interventions targeted at alleviating patients' misconceptions regarding susceptibility to $\mathrm{CHD}$, benefits of exercise and lack of personal control are highly recommended.

Notwithstanding the importance of these findings, none of the illness cognitions assessed in the current study was able to explain the difference in health promoting behaviors between the Jewish majority and the Arab minority in our sample. Our findings among cardiac patients are consistent with those of another recent study which also demonstrated the inability of health-related perceptual variables to explain ethnic differences in physical activity, this time within the general population [28].

The following limitations of our study should be considered. First, the response rate, although generally favorable, was lower among those transferred for intervention, among those admitted for unstable angina, and among women, especially Arab women. Second, the lower participation rates of Arab patients in CPRP, a phenomenon well recognized among ethnic minorities, affected the power to adequately explore interactions of ethnicity with illness cognition. "Third, in our analysis we incorporated a dichotomous yes/no response based on levels of reported exercise at follow up, while controlling for baseline level activity. We deliberately refrained from predicting actual levels of physical activity (energy expenditure), as the focus of the current publication was the stage of change in which 
an actual action is taken and the person is acquiring a new health behavior, in this instance from sedentary to active lifestyle". An additional limitation is the lack of data regarding length of participation in CPRP. Estimates were made at the follow up interview and the minimum period to count as participation was one month. Actual lengths were quite variable including many patients who continue ongoing participation as part of their life style change. Finally, the current study did not distinguish between Jewish immigrants and veteran Israelis although lower rates of participation in CPRP have been demonstrated among immigrants [37]. All these limitations should be taken into account in future research.

\section{Conclusions}

IC should be taken into account in future interventions to promote physical activity and participation in CPRP for both ethnic groups. The finding that the strong ethnic difference in exercise habits and in participation in CPRP still persists beyond the psychosocial determinants and the illness representations, suggests the existence of other explanatory pathways such as psychological state or cultural world views. Further studies are needed in order to elucidate this issue for the benefit of both populations.

\section{Competing interests}

The authors declare that they have no competing interests.

\section{Authors' contributions}

OR participated in the creation of the study's concept and design, organized and took part in the data collection, carried out statistical analysis, took part in the interpretation of the data, and drafted the manuscript. NV participated in the creation of the study's concept and design, provided advice and guidance on statistical and psychological issues, took part in the interpretation of the data, and critically revised the draft. ML participated in the creation of the study's concept and design, supervised the data collection from a medical perspective, took part in the interpretation of the data, critically revised the draft, and helped obtain funding. AK contributed to the conception of the study, provided medical advice during the data acquisition/collection phase, and helped in the design of the questionnaires. MM took part in the interpretation of the data, critically revised the draft, supervised the study, and obtained funding. JDK contributed to the study's conception and design, advised on statistical and epidemiological issues, took part in the interpretation of the data, and critically revised the draft. All authors read and approved the final manuscript.

\section{Funding}

This study was supported by grants from the Israel National Institute for Health Policy and Health Services Research (NIHP) and from the Israel Heart Fund.

\section{Author details \\ ${ }^{1}$ Hebrew University-Hadassah School of Public Health and Community Medicine, Ein Kerem, Jerusalem, Israel. ${ }^{2}$ Clalit Research Institute, Tel-Aviv, Israel. ${ }^{3}$ Department of Cardiology, Meir Medical Center, Kfar-Saba, Israel. ${ }^{4}$ Department of Psychology, Bar-Ilan University, Ramat-Gan, Israel. ${ }^{5}$ Department of Cardiology, N.Y.U. School of Medicine, New York, USA.}

Received: 6 May 2013 Accepted: 8 October 2013 Published: 12 October 2013

\section{References}

1. Lozano R, Naghavi M, Foreman K, Lim S, Shibuya K, Aboyans V, et al: Global and regional mortality from 235 causes of death for 20 age groups in
1990 and 2010: a systematic analysis for the global burden of disease study 2010. Lancet 2012, 380:2095-2128.

2. Goldberger N, Aburbeh M, Haklali Z: Leading Causes of Death in Israel 2000-2010. Ministry of health, Heallth Informatiion Department (Hebrew); 2013.

3. Eyre H, Kahn R, Robertson RM, Clark NG, Doyle C, Hong Y, et al: Preventing cancer, cardiovascular disease, and diabetes: a common agenda for the american cancer society, the American diabetes association, and the American heart association. Circulation 2004, 109:3244-3255.

4. Smith SC Jr, Blair SN, Bonow RO, Brass LM, Cerqueira MD, Dracup K, et al: AHA/ACC guidelines for preventing heart attack and death in patients with atherosclerotic cardiovascular disease: 2001 update. A statement for healthcare professionals from the american heart association and the american college of cardiology. J Am Coll Cardiol 2001, 38:1581-1583.

5. Dergance JM, Mouton CP, Lichtenstein MJ, Hazuda HP: Potential mediators of ethnic differences in physical activity in older Mexican Americans and European Americans: results from the San Antonio longitudinal study of aging. J Am Geriatr Soc 2005, 53:1240-1247.

6. Lee J: An ethnic-sensitive approach for the promotion of a healthy lifestyle: is it warranted? J Hum Hypertens 2008, 22:587-589.

7. Anderson JL, Adams CD, Antman EM, Bridges CR, Califf RM, Casey DE Jr, et al: 2012 ACCF/AHA focused update incorporated into the ACCF/AHA 2007 guidelines for the management of patients with unstable angina/ Non-ST-elevation myocardial infarction: a report of the American college of cardiology foundation/American heart association task force on practice guidelines. J Am Coll Cardiol 2013, 61:e179-e347.

8. Antman EM, Anbe DT, Armstrong PW, Bates ER, Green LA, Hand M, et al: ACC/AHA guidelines for the management of patients with ST-elevation myocardial infarction; a report of the American college of cardiology/ American heart association task force on practice guidelines (committee to revise the 1999 guidelines for the management of patients with acute myocardial infarction). J Am Coll Cardiol 2004, 44:E1-E211.

9. Suaya JA, Shepard DS, Normand SL, Ades PA, Prottas J, Stason WB: Use of cardiac rehabilitation by medicare beneficiaries after myocardial infarction or coronary bypass surgery. Circulation 2007, 116:1653-1662.

10. Mochari H, Lee JR, Kligfield P, Mosca L: Ethnic differences in barriers and referral to cardiac rehabilitation among women hospitalized with coronary heart disease. Prev Cardiol 2006, 9:8-13.

11. Chauhan U, Baker D, Lester $H$, Edwards R: Exploring uptake of cardiac rehabilitation in a minority ethnic population in England: a qualitative study. Eur J Cardiovasc Nurs 2010, 9:68-74.

12. Reges O, Vilchinsky N, Leibowitz M, Khaskia A, Mosseri M, Kark JD: Arab-Jewish differences in attending cardiac rehabilitation programs following acute coronary syndrome. Int J Cardio/ 2013, 163:218-219.

13. Naidoo J, Wills J: Health promotion, foundations for practice. 2nd edition. London: Bailliere Tindale; 2000:219-240.

14. Becker MH: The health belief model and personal health behavior. Health Educ Monogr 1974, 2(4):324-508.

15. Janz NK, Becker MH: The health belief model: a decade later. Health Educ Q 1984, 11:1-47.

16. Petrie KJ, Weinman J, Sharpe N, Buckley J: Role of patients' view of their illness in predicting return to work and functioning after myocardial infarction: longitudinal study. BMJ 1996, 312:1191-1194.

17. Okasha A: The individual versus the family: an islamic and traditional societies perspective. In Medicine of the Person: Faith, Science and Values in Health Care Provision. Edited by Cox J, Campbell AV, Fulford BWM. U.K: London: Jessica Kingsley Publishers; 2006:110-124.

18. Leventhal H, Nerenz DR, Steele DJ: Illness representations and coping with health threats. In Handbook of Psychology and Health, Volume IV, Social Psychological Aspects of Health. Edited by Baum A, Taylor SE, Singer JE. Hillsdale, NJ: Erlbaum; 1984:219-252.

19. Lau RR, Bernard TM, Hartman KA: Further explorations of common-sense representations of common illnesses. Health Psychol 1989, 8:195-219.

20. Cooper A, Lloyd G, Weinman J, Jackson G: Why patients do not attend cardiac rehabilitation: role of intentions and illness beliefs. Heart 1999 82:234-236

21. Cooper AF, Weinman J, Hankins M, Jackson G, Horne R: Assessing patients' beliefs about cardiac rehabilitation as a basis for predicting attendance after acute myocardial infarction. Heart 2007, 93:53-58.

22. French DP, Cooper A, Weinman J: Illness perceptions predict attendance at cardiac rehabilitation following acute myocardial infarction: a systematic review with meta-analysis. J Psychosom Res 2006, 61:757-767. 
23. Stafford L, Jackson HJ, Berk M: Illness beliefs about heart disease and adherence to secondary prevention regimens. Psychosom Med 2008, 70:942-948.

24. Oldridge NB, Streiner DL: The health belief model: predicting compliance and dropout in cardiac rehabilitation. Med Sci Sports Exerc 1990, 22:678-683.

25. Hiatt AM, Hoenshell-Nelson N, Zimmerman L: Factors influencing patient entrance into a cardiac rehabilitation program. Cardiovasc Nurs 1990, 26:25-29. discussion 30.

26. Herber OR, Jones MC, Smith K, Johnston DW: Assessing acute coronary syndrome patients' cardiac-related beliefs, motivation and mood ove time to predict non-attendance at cardiac rehabilitation. J Adv Nurs 2012, 68:2778-2788

27. Jolly K, Greenfield SM, Hare R: Attendance of ethnic minority patients in cardiac rehabilitation. J Cardiopulm Rehabil 2004, 24:308-312.

28. Mathieu RA, Powell-Wiley TM, Ayers CR, McGuire DK, Khera A, Das SR, et al: Physical activity participation, health perceptions, and cardiovascular disease mortality in a multiethnic population: the Dallas heart study. Am Heart J 2012, 163:1037-1040.

29. Reges O, Vilchinsky N, Leibowitz M, Khaskia A, Mosseri M, Kark JD: Systemic determinants as barriers to participation in cardiac prevention and rehabilitation services after Acute Coronary Syndrome. Int J Cardiol 2013, 9. 10.1016/j.jicard.2013.07.056. [Epub ahead of print].

30. Adler NE, Epel ES, Castellazzo G, Ickovics JR: Relationship of subjective and objective social status with psychological and physiological functioning: preliminary data in healthy white women. Health Psychol 2000, 19:586-592.

31. Ostrove JM, Adler NE, Kuppermann M, Washington AE: Objective and subjective assessments of socioeconomic status and their relationship to self-rated health in an ethnically diverse sample of pregnant women. Health Psychol 2000, 19:613-618.

32. Burazeri G, Goda A, Sulo G, Stefa J, Kark JD: Financial loss in pyramid savings schemes, downward social mobility and acute coronary syndrome in transitional Albania. J Epidemiol Community Health 2008, 62:620-626.

33. Taylor HL, Jacobs DR Jr, Schucker B, Knudsen J, Leon AS, Debacker G: A questionnaire for the assessment of leisure time physical activities. J Chronic Dis 1978, 31:741-755.

34. Mirotznik J, Feldman L, Stein R: The health belief model and adherence with a community center-based, supervised coronary heart disease exercise program. J Community Health 1995, 20:233-247.

35. Moss-Morris R, Weinman J, Petrie KJ, Horne R, Cameron LD, Buick D: The revised illness perception questionnaire (IPQ-R). Psychol Health 2002, 17:1-16.

36. Stuart-Shor EM, Berra KA, Kamau MW, Kumanyika SK: Behavioral strategies for cardiovascular risk reduction in diverse and underserved racial/ethnic groups. Circulation 2012, 125:171-184.

37. Gendler Y, Geulayov G, Ziv A, Novikov I, Dankner R: A multicenter intervention study on referral to cardiac rehabilitation after coronary artery bypass graft surgery: a 1-year follow-up of rehabilitation rates among USSR-born and veteran Israeli patients. Harefuah 2012, 151:511-517. 58, 57.

doi:10.1186/1471-2458-13-956

Cite this article as: Reges et al:: Illness cognition as a predictor of exercise habits and participation in cardiac prevention and rehabilitation programs after acute coronary syndrome. BMC Public Health 2013 13:956.

\section{Submit your next manuscript to BioMed Central and take full advantage of:}

- Convenient online submission

- Thorough peer review

- No space constraints or color figure charges

- Immediate publication on acceptance

- Inclusion in PubMed, CAS, Scopus and Google Scholar

- Research which is freely available for redistribution

Submit your manuscript at www.biomedcentral.com/submit 